\title{
Immature stages of the butterfly Erina gilesi (M.R. Williams \& Bollam, 2001) (Lepidoptera: Lycaenidae): description and comparative morphology of Erina species
}

\author{
Michael F. Braby ${ }^{1,2}$ and Rod Eastwood ${ }^{3}$ \\ 1 Division of Ecology and Evolution, Research School of Biology, The Australian National University, \\ Acton, ACT 0200, Australia. \\ 2 The Australian National Insect Collection, GPO Box 1700, Canberra, ACT 2601, Australia. \\ ${ }^{3}$ Collections and Research, Western Australian Museum, 49 Kew Street, Welshpool, Western Australia \\ 6106, Australia.
}

Corresponding author: michael.braby@anu.edu.au

\begin{abstract}
The lycaenid butterfly Erina gilesi (Williams \& Bollam, 2001) is endemic to southwestern Western Australia where it is a host specialist of the vine Cassytha racemosa (Lauraceae). We describe, illustrate and compare the immature stages of E. gilesi from two sites south of Perth with other members of the genus. We also illustrate and document variation in larval colour pattern in E. erina (Fabricius, 1775) and E. delospila (Waterhouse, 1903) for the first time. The immature stages of E. gilesi are most similar to its sister species, E. hyacinthina (Semper, 1879), but the late instar larvae differ in having a pair of conspicuous white dorsolateral lines on the body, and the reddish dorsal patches on abdominal segments 1 and 6, which when present, are simple and not raised into projections. The biology of E. gilesi indicates that adults are seasonal and partially bivoltine, with a facultative pupal diapause. A review of larval food plant-butterfly associations indicates that each species of Erina Swainson, 1833 tend to specialise on different species of Cassytha, and generally only one or two plant species are utilised throughout the geographical range of each species/ subspecies, suggesting ecological differentiation in the genus.
\end{abstract}

KEYWORDS: Candalidini, Cassytha, Lauraceae, life history, pupal diapause, Western Australia

\section{INTRODUCTION}

The butterfly genus Erina Swainson, 1833 contains six species, most of which are endemic to Australia (Braby et al. 2020). They occur in a variety of temperate and tropical woodlands and heathy woodlands where the larvae feed exclusively on Cassytha (Lauraceae) (Table 1). The Western Dusky-blue, Erina gilesi (Williams \& Bollam, 2001), is endemic to the southwestern Australian biodiversity hotspot, defined by Hopper and Gioia (2004), where it has been recorded from a limited area along the west and south-west coast between the Porongurups and Stirling Ranges, West Cape Howe and near Perth, Western Australia (Edwards and Kerr 1978; Williams et al. 1993; Williams et al. 1997; Braby 2000; Williams and Bollam 2001; Williams and Williams 2006; Williams et al. 2012). Recorded localities include Yalgorup National Park, Lake Preston,
Myalup, Dunsborough, Yallingup, Margaret River, Augusta, Windy Harbour, Cosy Corner, West Cape Howe, as well as inland at Glen Forrest on the Darling Range east of Perth, south to Manjedal Brook, Hoffmans Mill, Manjimup, Pemberton, the Porongurups and Stirling Range National Park. It occurs in eucalypt open-forest and woodland, as well as heathland, where the larval food plant Cassytha racemosa Nees commonly grows as a twining hemiparasite (Williams and Bollam 2001). The taxon was originally described by Williams and Bollam (2001) as a subspecies of Erina hyacinthina (Semper, 1879), but Williams and Williams (2006) suggested its status may warrant investigation after both $E$. gilesi and E. hyacinthina were found together on Mondurup Peak, Stirling Range, with no evidence of hybridisation. Subsequently, Braby et al. (2020) proposed that E. gilesi be treated as a distinct species based on fundamental differences in genitalic 
morphology and adult phenotype (15 characters), phylogenetic pattern according to molecular data and level of pairwise divergence according to mtDNA $(2.8 \%$ for COI), and its narrowly sympatric distribution with $E$. hyacinthina. The immature stages of E. gilesi, however, have not been compared, with only the egg and early instar larvae (instars I and II) so far described (Williams and Bollam 2001). Thus, comparative morphology of the immature stages may provide additional evidence in support of the two species hypothesis proposed by Braby et al. (2020).

The aim of this paper is to describe, illustrate and compare the immature stages of E. gilesi with other members of the genus, particularly E. hyacinthina. We also illustrate and document variation in larval colour pattern in E. erina (Fabricius, 1775) and E. delospila (Waterhouse, 1903) for the first time. Life histories have been documented for all species of Erina except for E. gilesi.

\section{MATERIALS AND METHODS}

Live material was collected from two field sites: at Lake Preston (sea-level), Myalup c. $120 \mathrm{~km} \mathrm{~S}$. of Perth, Western Australia during 25 November 2019 to 16 December 2019, and Hoffmans Mill (270 m asl) on the Darling Range c. 115 km SSE. of Perth during 9 December 2019 to 11 January 2020. The habitat at Lake Preston (Figures 1-2) consists of open woodland dominated by Tuart

TABLE 1 Summary of larval food plants used by Erina spp. in Australia. Larval food plants are divided into two groups: primary refers to those that are used predominantly throughout the geographical range of the butterfly species or on which the immature stages are most frequently recorded where two or more food plants grow in sympatry. For the other food plants, the broad distribution is provided (at the state or territory scale), although in most circumstances these records refer to very localised associations at much smaller spatial scales.

\begin{tabular}{|c|c|c|c|}
\hline Butterfly species & Primary food plant & Other food plants & References \\
\hline Erina delospila & Cassytha capillaris ${ }^{1,2}$ & & $\begin{array}{l}\text { Braby }(1995,2011) \text {, } \\
\text { Grund and Hunt (2001) }\end{array}$ \\
\hline Erina acasta & Cassytha glabella ${ }^{3}$ & $\begin{array}{l}\text { Cassytha pubescens (VIC, SA), } \\
\text { C. peninsularis (SA) }\end{array}$ & $\begin{array}{l}\text { Fisher (1978), Grund (1996), } \\
\text { Braby (2000), Field (2013) }\end{array}$ \\
\hline Erina gilesi & Cassytha racemosa & & $\begin{array}{l}\text { Williams and Bollam (2001), } \\
\text { this work }\end{array}$ \\
\hline Erina hyacinthina hyacinthina & Cassytha pubescens & Cassytha melantha (VIC) & $\begin{array}{l}\text { Braby (2000), Field (2013), } \\
\text { Braby et al. (in press) }\end{array}$ \\
\hline Erina hyacinthina simplex & Cassytha melantha & $\begin{array}{l}\text { Cassytha peninsularis (SA), } \\
\text { C. findersii (SA), } \\
\text { C. aurea (WA) }\end{array}$ & $\begin{array}{l}\text { Fisher (1978), } \\
\text { Grund (1997, 1998, 2001, 2009), } \\
\text { Williams et al. (2000), } \\
\text { Braby and Edwards (2006) }\end{array}$ \\
\hline Erina geminus geminus & Cassytha filiformis ${ }^{4}$ & Cassytha pubescens (NSW) & Edwards (1980), Braby $(1995,2011)$ \\
\hline Erina geminus gagadju & Cassytha filiformis & Cassytha capillaris (NT) & Braby $(2011,2017)$ \\
\hline Erina erina & Cassytha filiformis ${ }^{5}$ & $\begin{array}{l}\text { Cassytha capillaris (WA, NT), } \\
\text { C. aurea (WA) }\end{array}$ & $\begin{array}{l}\text { Grund (1998), } \\
\text { Grund and Hunt (2001), } \\
\text { Braby }(1997,2000,2011)\end{array}$ \\
\hline
\end{tabular}

1 The record of Cassytha filiformis for Erina delospila from the Burra Range, Qld (Braby 1995) is erroneous and refers to C. capillaris (see Braby 2011).

2 The record of Cassytha glabella for Erina delospila from Broome, WA (Braby 1995) is erroneous and most likely refers to C. capillaris.

${ }^{3}$ The record of Cassytha filiformis for Erina acasta from Port Denison, WA (Grund 1998) is erroneous and most likely refers to C. glabella.

4 The record of Cassytha pubescens for Erina geminus geminus from the Burra Range, Qld (Braby 1995) is erroneous and refers to C. filiformis (see Braby 2011).

5 The records of Cassytha pubescens for Erina erina from several locations in northern Queensland (Braby 1997) are erroneous and refer to C. filiformis (see Braby 2011). 

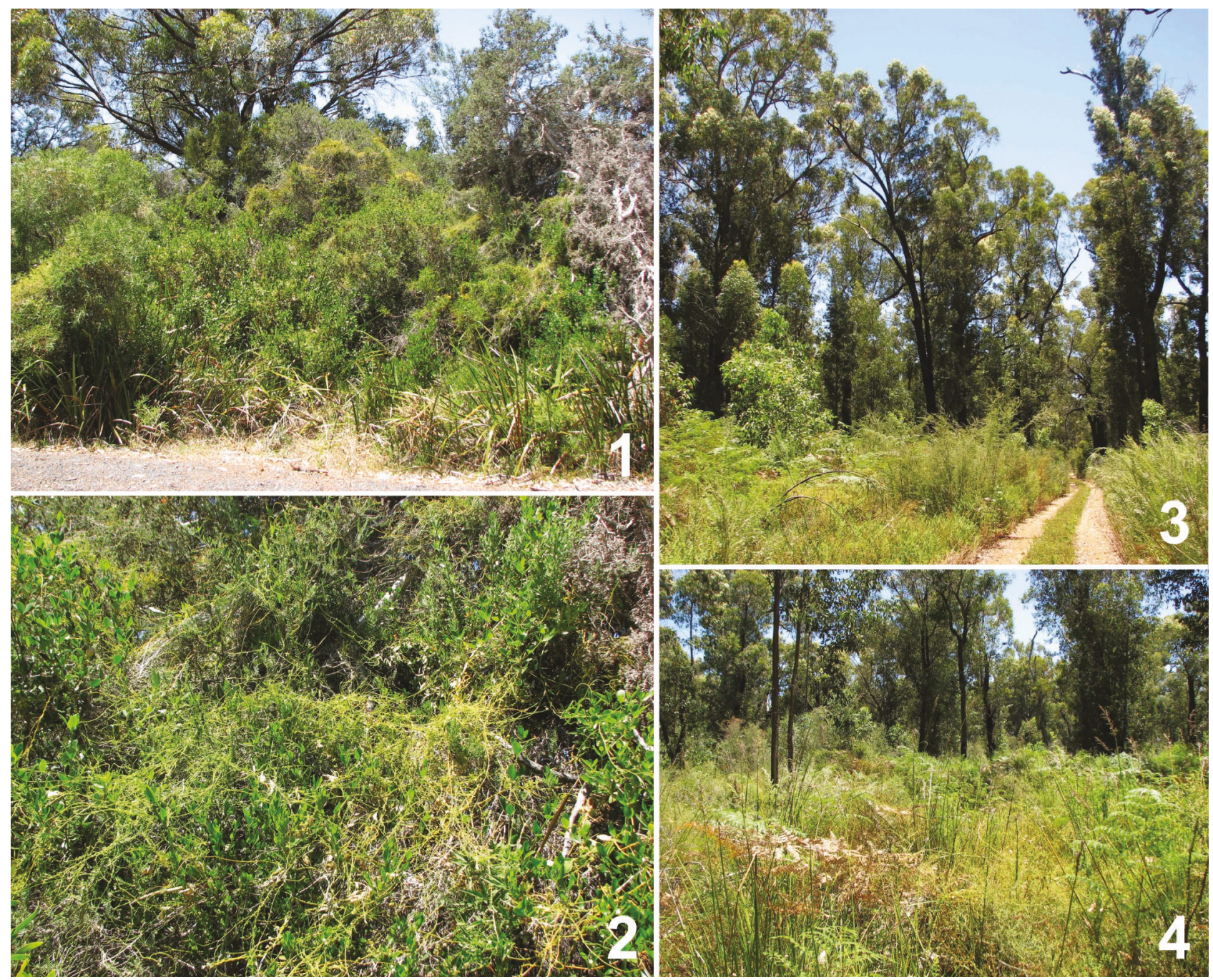

FIGURES 1-4 Habitats and larval food plant of Erina gilesi in south-western Western Australia: 1) open woodland dominated by Tuart (Ecalyptus gomphocephala) and Peppermint (Agonis flexuosa) with small Melaleuca trees cloaked in Cassytha racemosa in lake-fringing vegetation at Lake Preston, Myalup; 2) larval food plant, Cassytha racemosa, Lake Preston; 3-4) riverine woodland dominated by Yarri (Eucalyptus patens) with a mixed understorey of Agonis sp., Astartea, Mirbelia dilatata, Gahnia sp. and Pteridium esculentum along a watercourse at Hoffmans Mill. Note the Hoffmans Mill site was extensively burnt by wildfire in January 2016. (Images R. Eastwood.)

(Eucalyptus gomphocephala) and Peppermint (Agonis flexuosa), with small Melaleuca trees and a mixed understorey of Lepidosperma gladiatum, Gahnia sp., Acacia spp., Alyxia buxifolia, Spyridium globulosum and Persoonia longifolia. The larval food plant, the vine Cassytha racemosa, grows patchily along the western fringe of the lake where it cloaks the Melaleuca trees and understorey shrubs. In contrast, the habitat at Hoffmans Mill (Figures 3-4) comprises riverine woodland dominated by Yarri (Eucalyptus patens), with a mixed understorey of Agonis spp., Astartea spp., Mirbelia dilatata, Gahnia sp. and Pteridium esculentum along a watercourse. Cassytha racemosa grows in high density in the understorey, as well as on some emergent shrubs and small trees. The site was burnt extensively in January 2016.
Females were individually placed inside clear plastic bags with cuttings of the larval food plant on which eggs were laid. Fresh tendrils and flower buds of the larval food plant were also examined and searched in the field for presence of eggs and larvae. Larvae were reared individually, initially in small plastic vials $(40 \mathrm{~mm}$ diam. x $60 \mathrm{~mm}$ high) and then, in the later instars, larger plastic containers $(120 \mathrm{~mm}$ × $80 \mathrm{~mm}$ x $60 \mathrm{~mm})$. The containers were supplied with fresh cuttings of Cassytha spp., which was changed every 2-3 days - larvae reared in Perth were fed on C. racemosa, whereas those reared in Canberra were offered C. pubescens.

Voucher specimens have been lodged in the Western Australian Museum (7 $\hat{0}, 4$ o: registration numbers WAM E105353-WAM E105363), as well as the Australian National Insect Collection, Canberra (4 ô). 
TAXONOMY

Family Lycaenidae Leach, 1815

Subfamily Theclinae Swainson, 1831

Tribe Candalidini Eliot, 1973

Genus Erina Swainson, 1833

Erina gilesi (M.R. Williams \& Bollam, 2001)

Figures 5-22

Candalides hyacinthinus gilesi M.R. Williams \& Bollam, 2001: 49-53, figures 1-4.

Candalides hyacinthinus gilesi M.R. Williams \& Bollam: Braby, 2004: 261-262; Williams and Williams, 2006: 56; Orr and Kitching, 2010: 262; Braby, 2010: 14, 72; Williams et al., 2012: 60-61; Braby, 2016: 290-291.

Erina gilesi (M.R. Williams \& Bollam): Braby et al., 2020: 714-716.

\section{DIAGNOSIS}

The immature stages of Erina gilesi (Figures 5-22) are similar to those of E. hyacinthina (Figures 23-37), but they diverge in the late instar larvae (instars III-V). In $E$. gilesi, the larva has two conspicuous white longitudinal lines, whereas in E. hyacinthina these lines are usually absent or, if present, yellow and only faintly visible. In E. gilesi, the two small dark reddish dorsal patches or spots on abdominal segments 1 and 6 , when present, are not raised from the surface, whereas in E. hyacinthina these patches appear as projections, are larger and more variable in extent (sometimes being present only on A1 and absent on A6), and are sometimes bordered laterally by white and dark red dorsolateral streaks. Overall, the larva of E. gilesi, like E. acasta (Cox, 1873), is less variable in colour pattern; in E. hyacinthina the larva is usually devoid of conspicuous longitudinal markings or has a faint yellow dorsolateral line, but occasionally there may be a broken white dorsolateral line edged below by a broken dark reddish line, from the metathorax to abdominal segment 6. In E. acasta, which occurs parapatrically with E. gilesi, the larva (Figures 38-40) has a pair of conspicuous yellow longitudinal lines, rather than the white lines in E. gilesi.

\section{DESCRIPTION}

\section{Egg}

$0.6 \mathrm{~mm}$ diameter by $0.4 \mathrm{~mm}$ high $(n=22)$; pale green when laid, later changing to white; subspherical, with micropylar region slightly depressed, coarse reticulate pattern of facets comprising deep quadrangular- or pentagonal-shaped polygons separated by raised ridges (Figure 5).

\section{First instar larva}

$1.2 \mathrm{~mm}$ long; head pale brown, hidden beneath prothorax; prothoracic plate grey with several colourless setae; mesothorax yellowish-brown with two pairs of long, recurved dorsolateral setae, one on either side; metathorax and abdominal segments 1-7 yellowishbrown, each segment bearing a pair of long, recurved brown dorsal setae, laterally fringed with one long and two shorter colourless setae, and a few minute brown dots; abdominal segments 7 and 8 each with a long, recurved brown lateral seta; anal plate grey with several colourless setae (Figure 6).

\section{Second instar larva}

$3.9 \mathrm{~mm}$ long; prothoracic plate pale green, diamondshaped; mesothorax, metathorax and abdominal segments 1-6 pale lime-green with a broad whitish dorsal band enclosing a narrow reddish middorsal line and obscure red subdorsal markings, particularly on A1 and A6, each segment with two pairs of long, recurved brown dorsal setae and laterally fringed with colourless setae; abdominal segments 6-8 lime-green with obscure red lateral markings; anal plate reddish; entire body with a narrow white lateral line and covered with minute brown dots (Figures 7-8).

\section{Third instar larva}

$8.0 \mathrm{~mm}$ long; similar to instar IV, but dorsal area between the pair of white dorsolateral lines paler, almost forming a broad whitish dorsal band from mesothorax to abdominal segment 6; a narrow white lateral line along length of body (Figures 9, 10).

\section{Fourth instar larva}

$12 \mathrm{~mm}$ long; similar to instar V (Figures 11-13).

\section{Fifth instar larva}

$15 \mathrm{~mm}$ long; head pale brown, concealed beneath prothorax; prothorax green, unmarked; mesothorax, metathorax and abdominal segments 1-6 green, each with a narrow darker green middorsal line, a faint pale green subdorsal streak, followed by a conspicuous white dorsolateral line edged below darker green; abdominal segments 7-10 green, somewhat flattened with a darker green middorsal line, obscure pale green subdorsal streaks on A7-A9, Newcomber's Organ present on A7, a pair of tentacular organs on $\mathrm{A} 8$, and a darker green anal plate on A10; body covered in dense short marginal hairs and minute dark brown secondary setae; spiracles pale brown (Figures 14-19).

\section{Pupa}

$10.1-12.3 \mathrm{~mm}$ long $(\bar{x}=11.1 \mathrm{~mm})$ by $4.6-5.6 \mathrm{~mm}$ wide $(\bar{x}=5.0 \mathrm{~mm})(n=31)$; grey-brown or brown with darker brown-black markings; head with anterior end flattened into a flange with a prominent median indentation; thorax with a pair of short slender middorsal projections; metathorax with a black dorsal ridge; abdomen with a dorsal ridge, more prominent on segments $1-3$, and a conspicuous lateral flange, weakly upturned; spiracles cream (Figures 20-22). 


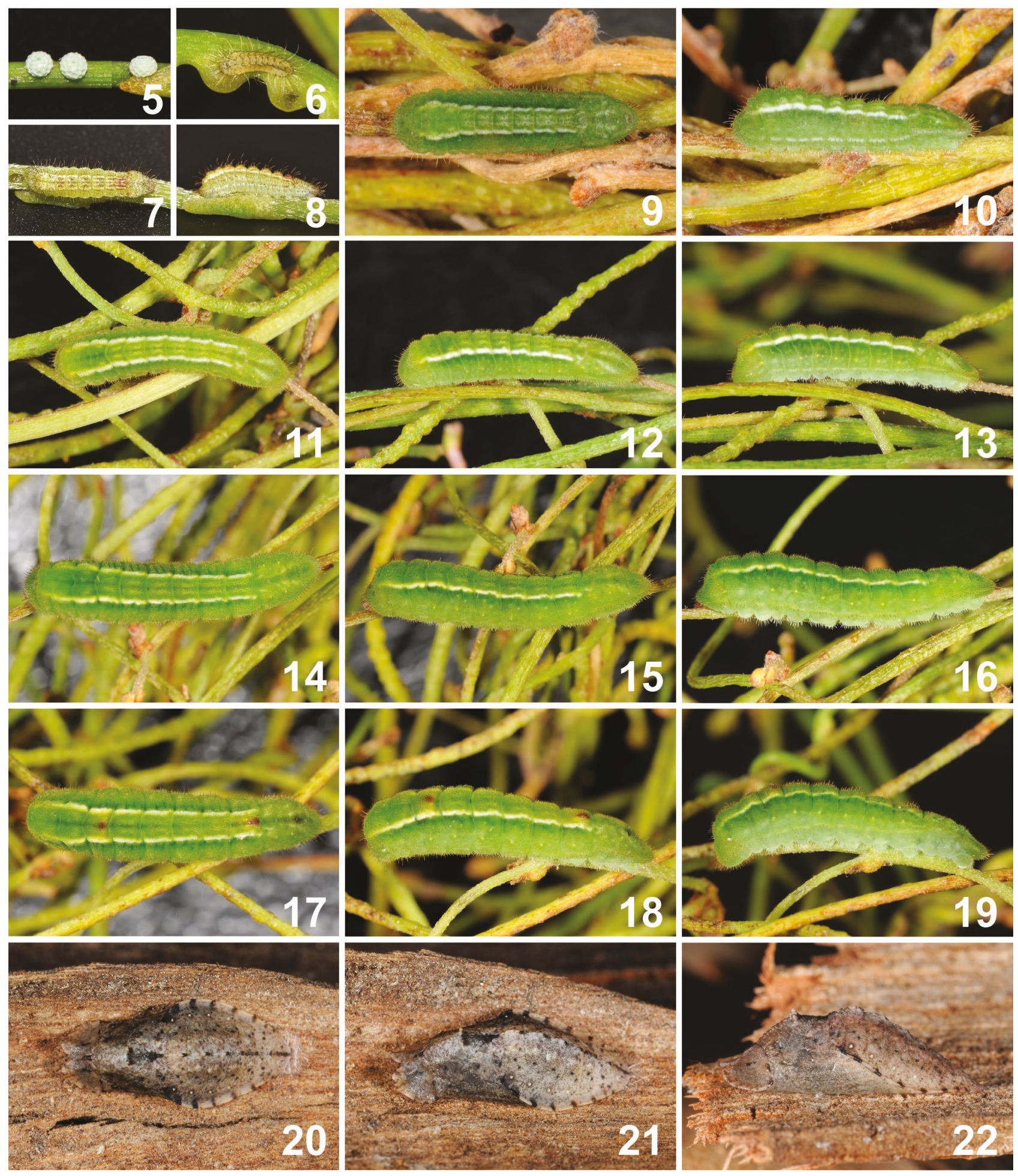

FIGURES 5-22 Immature stages of Erina gilesi: 5) egg; 6) first instar larva, dorsal view; 7-8) second instar larva, dorsal and lateral views; 9-10) third instar larva, dorsal and lateral views; 11-13) fourth instar larva, dorsal, dorsolateral and lateral views; 14-16) fifth instar larva, dorsal, dorsolateral and lateral views; 17-19) fifth instar larva, dorsal, dorsolateral and lateral views; 20-22) pupa, dorsal, dorsolateral and lateral views. (Images 5-8 courtesy Jean Hort; 9-22 M.F. Braby). 


\section{VARIATION}

The larvae (instars III-V) sometimes have two reddish dorsal patches, on abdominal segments 1 and 6 , and occasionally an additional reddish dorsal patch on abdominal segment 8 (Figures 17-19). Most late instar larvae are uniformly green, but one final instar larva collected from Hoffmans Mill was yellow-green with distinct reddish spots on A1 and A6. Pupal colour varied according to the colour of the substrate on which the larva pupated.

\section{BIOLOGY}

The following field observations were made at the two sites south of Perth. Males were observed to either patrol across and around the understorey vegetation on which the Cassytha food plant was attached, or perch on prominent leaves of emergent vegetation where fresh green shoots of Cassytha were growing within c. $300 \mathrm{~mm}$. Males actively defended their territories from other males and returned to their perching sites after each male-male interaction to wait for females. They were most active on sunny days from 08:0015:00, with an apparent peak in abundance just after midday (13:00), when maximum temperatures were $<30^{\circ} \mathrm{C}$. However, they changed their perching sites and territories according to the position of the sun, avoiding shadows during the day. Freshly emerged females flew close to the understorey and along natural pathways in the breeding sites where they encountered males and mated immediately. Once mated, some females laid an egg or two at or near the mating site before flying off to spend most of their time in the understorey.

Eggs were usually laid singly, but occasionally in loose groups of two or three, on bracts, flower buds, new soft tendrils, stems and occasionally haustoria of the larval food plant growing in sheltered positions in the understorey. Eggs laid on flower buds were difficult to detect because their colour, size and shape closely matched the small new buds. On hatching, the first instar larvae chewed a small hole at the top of the egg through which they escaped, but they did not consume the remainder of the egg shell. The first instar larvae were uniformly straw coloured on hatching, but became more speckled as they grew before moulting to the second instar. First and second instar larvae fed by chewing a shallow pit into a fresh stem or tendril towards the tip of the vine. Presumably, they also imbibed the phloem that seeped into the pit. Later instar larvae consumed the entire tendril as they moved backwards along the stem. They also ate the flower buds. When reared in captivity, final instar larvae left the food plant and pupated beneath pieces of bark or on dead leaves, which suggests they pupate in the leaf litter in nature. The pupae were attached to a silken pad, spun on the substrate, by the anal hooks of abdominal segment 10 and a silken girdle spun over the junction between the metathorax and abdominal segment 1. Pupae were heard to stridulate; however, those that entered diapause did not stridulate.
Eggs laid by captive females hatched approximately one week later (range $6-8$ days, $\bar{x}=7.0 ; n=26$ ). Larvae completed development in 15-20 days $(\bar{x}=17.2 ; n=$ 26 ), with the pre-pupal stage lasting 2-3 days. Pupal duration varied: from a sample of 31 pupae, $16(52 \%)$ emerged directly within $12-18$ days $(\bar{x}=14.4)$, whereas the remaining 15 (48\%) entered diapause.

\section{DISCUSSION}

Erina gilesi belongs to a monophyletic group that includes five other species of Erina. According to a recent molecular phylogeny of the Candalidini, phylogenetic relationships of the six species of Erina are as follows: delospila $+($ acasta $+(($ gilesi + hyacinthina $)$ $+($ geminus + erina $)))($ Braby et al. 2020). Thus, E. gilesi is most closely related to E. hyacinthina, and this pair is sister to E. geminus (E.D. Edwards \& Kerr, 1978) and E. erina. Comparative differences between the immature stages of E. gilesi (Figures 5-22) and E. hyacinthina (Figures 23-37) support the species level status of the taxon recently proposed by Braby et al. (2020). Although the egg, first instar larva and pupa are indistinguishable between the two species, they diverge in the late instar larvae, with at least two character states unique to E. gilesi: (1) body with dorsolateral line white and conspicuous; and (2) abdominal segments 1 and 6 each with reddish dorsal patches, when present, simple and not raised into projections.

The larvae of E. geminus (Braby 2017, figures 21-29), E. erina (Figures 41-52) and E. delospila (Figures 53-67) from northern Australia are particularly variable, and perhaps more so than E. hyacinthina. Although all three species are allopatric with E. gilesi, larval identification can potentially be confusing. Braby (2011) noted that the larvae of E. erina and E. delospila were polymorphic, varying from green, through pale greenbrown, pale brown to pinkish-brown, and in the colour of the longitudinal (dorsal) lines and bands, but these forms or morphs have not previously been illustrated. In one form of E. erina, the dorsolateral lines are white (Figures 41-43), and thus it closely resembles E. gilesi. Larvae of E. delospila, E. acasta and E. erina lack the reddish dorsal patches or projections on abdominal segments 1 and 6 , and thus these three species can usually be distinguished from E. gilesi, E. hyacinthina and E. geminus, which typically have these structures. Larvae of E. delospila are characterised by the presence of a conspicuous purple or red dorsolateral line edged above with white, whereas in E. erina this feature, when present, appears as a broken line or series of spots from the metathorax to abdominal segment 6 (Figures 44, 47-52).

Erina gilesi larvae were not found in the company of ants in the field; however, they possess Newcomber's Organ and a pair of tentacular organs, which suggests the larvae may have a facultative association with ants, similar to other Erina species. Pupal stridulation also suggests the pupae may be associated with ants in their pupation sites, such as leaf litter. 

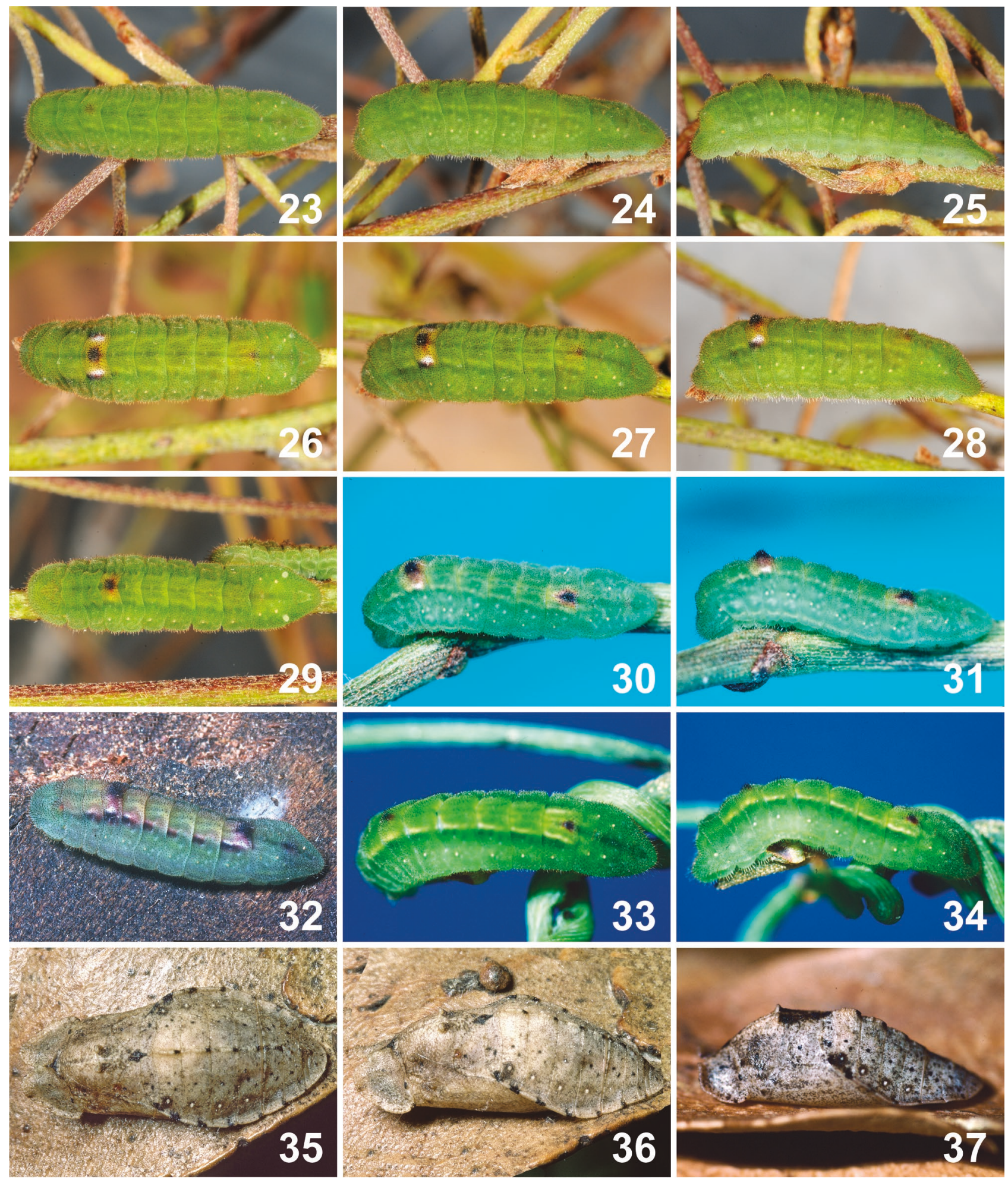

FIGURES 23-37 Final instar larva and pupa of Erina hyacinthina, showing variation in larval colour pattern. Note tentacular organs on abdominal segment 8 are everted in Figure 29. (Images: 23-31, 33, 34, 37 M.F. Braby; 32, 35, 36 L. Hunt.) 

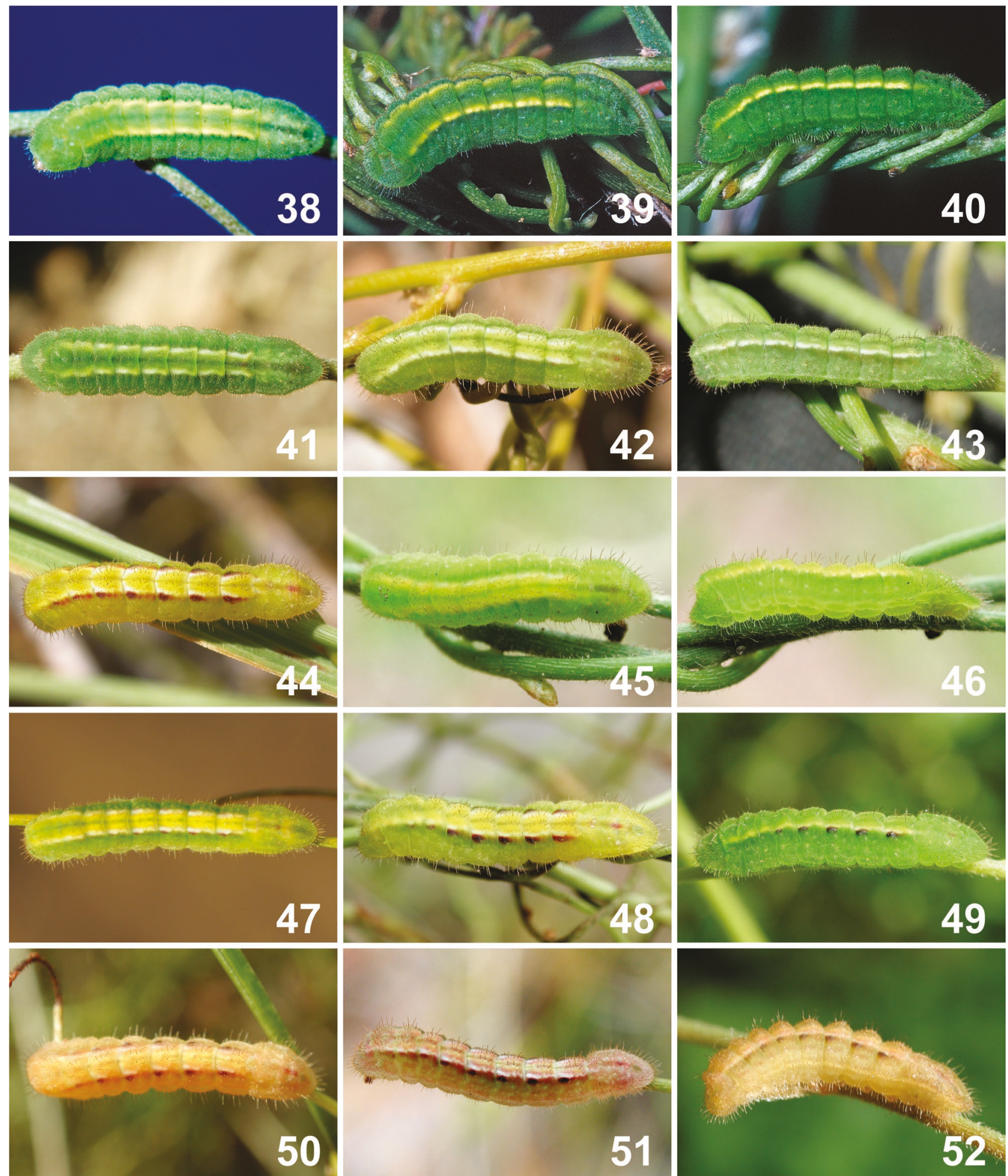

FIGURES 38-52 Final instar larva of Erina spp.: 38-40) E. acasta; 41-52) E. erina, showing variation in colour pattern. Forms of E. erina are as follows: 41-43) 'form 1' green with white longitudinal lines; 44) 'form 2' pale green with reddish-purple longitudinal lines; 45-46) 'form 3' green with yellow longitudinal lines; 47-48) 'form 4' pale green with reddish-purple longitudinal spots and yellow dorsal band; 49) 'form 5' green with reddish-purple longitudinal spots; 50-52) 'form 6' brown with reddish-purple longitudinal spots. (Photos: 38, 41-50 M.F. Braby; 39, 40 L. Hunt.) 

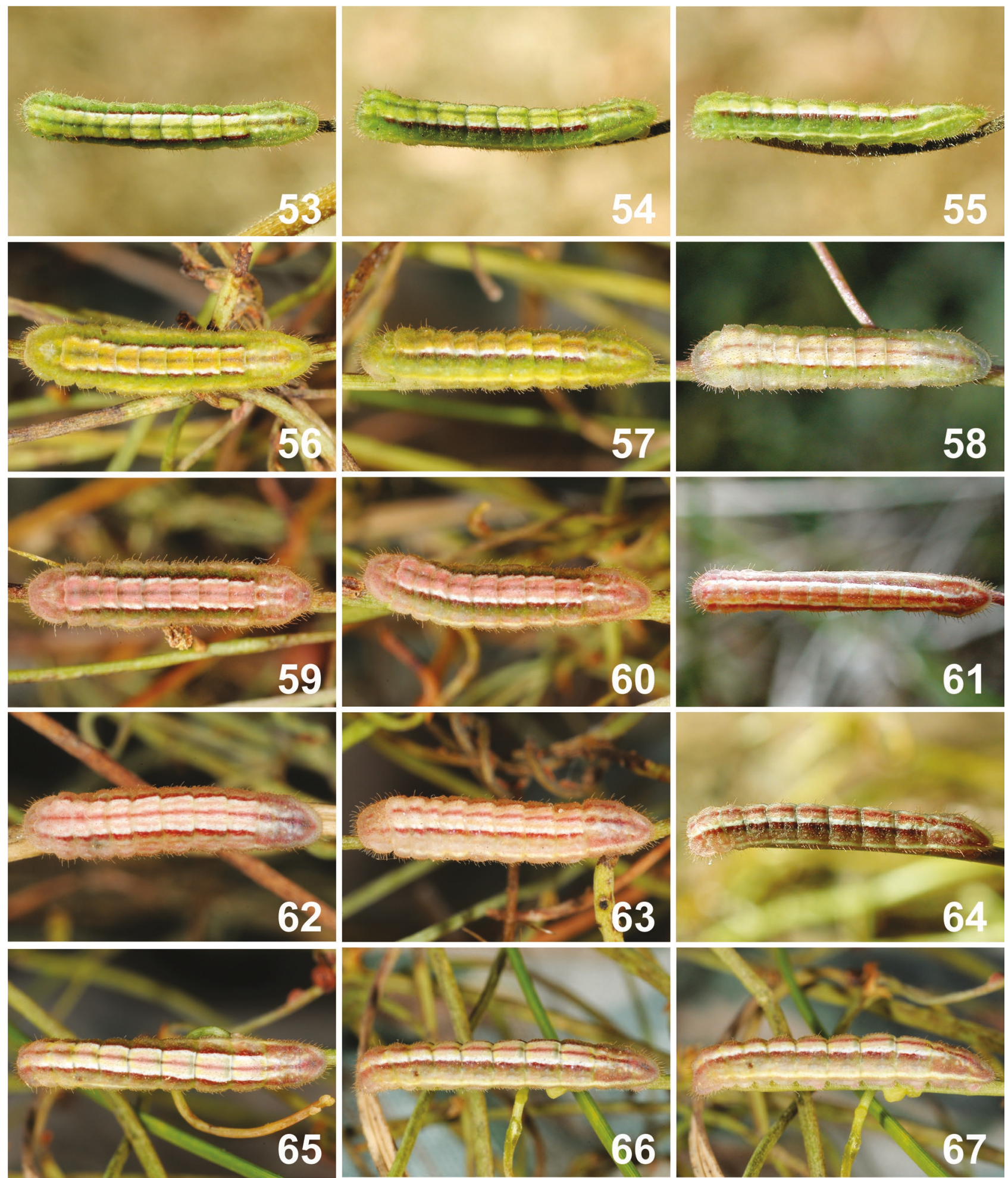

FIGURES 53-67 Final instar larva of Erina delospila, showing variation in larval colour pattern. Forms are as follows: 53-55) 'form 1' green with pale green dorsal band; 56-57) 'form 2' green with yellow dorsal band; (58) 'form 3' pale green with white dorsal band; 59-60) 'form 4' green with pink dorsal band; 61-64) 'form 5' pink-brown with pink dorsal band; 65-67) 'form 6' pink-brown with white dorsal band. (Photos: M.F. Braby.) 
Erina gilesi is seasonal and appears to be partially bivoltine, with a facultative pupal diapause. Based on our larvae reared in captivity it appears that approximately half of the population of the first generation develops directly, while the other half enters diapause. Williams and Bollam (2001) recorded the broad adult flight period from October to late January, but noted that the main activity period was approximately six weeks, from late November to early January, which coincides with the flowering period of the larval food plant. At the Hoffmans Mill site, adults were still flying on 29 January 2020, and in captivity adults continued to emerge well into February.

All species of Erina feed on Cassytha, with a total of nine plant species recorded for the butterfly genus as a whole (Table 1). Several food plant determinations in the past were incorrect due to taxonomic difficulties with Cassytha prior to the systematic revision of the genus by Weber (2007). Available data indicate that each Erina species tends to specialise on different species of Cassytha and generally only one or two plant species are used throughout the geographical range of each butterfly taxon (species or subspecies). Only three taxa (E. acasta, E. hyacinthina simplex (Tepper, 1882 ) and E. erina) are known to exploit three or more species of Cassytha. An exception to this general pattern of specialisation is the species pair E. geminus and E. erina, both of which mainly exploit C. filiformis; however, E. geminus only uses this food plant where it grows on sandstone, whereas E. erina occurs more widely in tropical and subtropical woodland habitats outside sandstone areas. These insect-plant associations suggest a degree of ecological differentiation in the genus Erina.

\section{ACKNOWLEDGEMENTS}

We thank Matt Williams and Andy Williams for providing locality data for the two Erina gilesi populations studied and for critically reviewing the manuscript. We also thank Fred and Jean Hort for plant identifications, Jean Hort for photographs of the egg and early instar larvae of E. gilesi, and the late Lindsay Hunt for photographs of the early stages of E. hyacinthina and E. acasta. Where appropriate, specimens were collected under the Department of Biodiversity, Conservation and Attractions Fauna Taking (Scientific or other Purposes) Licence numbers FO25000006-7 (employees and agents of the WAM) and FO25000042 issued to RE.

\section{REFERENCES}

Braby, M.F. (1995). The life history of Zetona delospila (Waterhouse) (Lepidoptera: Lycaenidae). The Australian Entomologist 22: 37-42.

Braby, M.F. (1997). New larval food plants for some butterflies (Lepidoptera) from northern and central Queensland, Australia. The Australian Entomologist 24: 97-108.
Braby, M.F. (2000). Butterflies of Australia. Their Identification, Biology and Distribution. CSIRO Publishing: Collingwood, Melbourne.

Braby, M.F. (2004). The Complete Field Guide to Butterflies of Australia. CSIRO Publishing: Collingwood, Melbourne.

Braby, M.F. (2010). The merging of taxonomy and conservation biology: a synthesis of Australian butterfly systematics (Lepidoptera: Hesperioidea and Papilionoidea) for the 21st century. Zootaxa (2707): 1-76. doi: 10.11646/ zootaxa.2707.1.1.

Braby, M.F. (2011). New larval food plant associations for some butterflies and diurnal moths (Lepidoptera) from the Northern Territory and eastern Kimberley, Australia. The Beagle, Records of the Museums and Art Galleries of the Northern Territory 27: 85-105.

Braby, M.F. (2016). The Complete Field Guide to Butterflies of Australia. Second Edition. CSIRO Publishing: Clayton South, Melbourne.

Braby, M.F. (2017). A new subspecies of Candalides geminus Edwards \& Kerr, 1978 (Lepidoptera: Lycaenidae) from the Northern Territory, Australia. Records of the Western Australian Museum 32(2): 207-216. doi: 10.18195/issn.03123162.32(2).2017.207-216.

Braby, M.F. and Edwards, E.D. (2006). The butterfly fauna of the Griffith district, a fragmented semi-arid landscape in inland southern New South Wales. Pacific Conservation Biology 12: 140-154. doi: 10.1071/PC060140.

Braby, M.F., Espeland, M., Müller, C.J., Eastwood, R., Lohman, D.J., Kawahara, A.Y., Maunsell, S.C. and Pierce, N.E. (2020). Molecular phylogeny of the tribe Candalidini (Lepidoptera: Lycaenidae): systematics, diversification and evolutionary history. Systematic Entomology 45: 703-722. doi: 10.1111/syen.12432.

Braby, M.F., Williams, M.R., Douglas, F., Beardsell, C. and Crosby, D.F. (in press). Changes in a peri-urban butterfly assemblage over 80 years near Melbourne, Australia. Austral Entomology 60.

Edwards, E.D. (1980). The early stages of Adaluma urumelia Tindale and Candalides geminus Edwards and Kerr (Lepidoptera: Lycaenidae). Australian Entomological Magazine 7: 17-20.

Edwards, E.D. and Kerr, J.F.R. (1978). A new species of Candalides from eastern Australia and notes on Candalides hyacinthinus (Semper) (Lepidoptera: Lycaenidae). Australian Entomological Magazine 4: 81-90.

Field, R.P. (2013). Butterflies: Identification and Life History. Museum Victoria, Melbourne.

Fisher, R.H. (1978). Butterflies of South Australia. Government Printer: Adelaide.

Grund, R. (1996). Range extensions, new foodplant recordings and biology for some South Australian butterflies. Victorian Entomologist 26: 93-100.

Grund, R. (1997). Additional range extensions, new foodplant recordings and biology for some rarer South Australian butterflies including the life history for Candalides cyprotus cyprotus (Oliff). Victorian Entomologist 27: 7-14.

Grund, R. (1998). New foodplant recordings and biological observations for some Western Australian butterflies. Victorian Entomologist 28: 65-68.

Grund, R. (2001). Wing colour dominance within Erina (Candalides) hyacinthina (Semper) (Lepidoptera: Lycaenidae). Victorian Entomologist 31: 90-91.

Grund, R. (2009). New range extensions and other data for selected butterflies and sun-moths from the Maralinga 
and far westcoast areas of South Australia. Victorian Entomologist 39: 108-114.

Grund, R. and Hunt, L. (2001). Some butterfly observations for the Kimberley and Tanami regions, Western Australia. Victorian Entomologist 31: 19-23.

Hopper, S.D. and Gioia, P. (2004). The southwest Australian floristic region: evolution and conservation of a global hot spot of biodiversity. Annual Review of Ecology, Evolution and Systematics 35: 623-650.

Orr, A.G. and Kitching, R.L. (2010). The Butterflies of Australia. Allen and Unwin: Sydney.

Weber, J.Z. (2007). Cassytha, Lauraceae. In Flora of Australia. Volume 2, Winteraceae to Platanaceae. (Ed. A.J.G. Wilson) pp. 117-136. Australian Biological Resources Study and CSIRO Publishing: Canberra and Collingwood, Melbourne.

Williams, A.A.E. and Williams, M.R. (2006). Records of butterflies (Lepidoptera) from inland and southern Western Australia. Victorian Entomologist 36: 53-58.
Williams, A.A.E., Williams, M.R. and Atkins A.F. (1997). Notes on some Western Australian butterflies. Victorian Entomologist 27: 44-49.

Williams, A.A.E., Williams, M.R. and Graham, A.J. (2000). Further notes on some Western Australian butterflies. Victorian Entomologist 30: 3-9.

Williams, A.A.E., Williams, M.R., Hay, R.W. and Tomlinson, A.G. (1993). Some distributional records and natural history notes on butterflies from Western Australia. Victorian Entomologist 23: 126-131.

Williams, A.A.E., Williams, M.R., Powell, R. and Walker, G. (2012). Rare butterflies of the south-west. Department of Environment and Conservation: Kensington, WA.

Williams, M.R. and Bollam, H.H. (2001). A new subspecies of Candalides hyacinthinus (Semper) (Lepidoptera: Lycaenidae) from Western Australia. The Australian Entomologist 28: 49-54.

MANUSCRIPT RECEIVED 10 JUNE 2020; ACCEPTED 31 AUGUST 2020. 